\title{
AJHPE special focus issue - call for papers: \\ Innovations in health professions education during the COVID-19 era
}

Guest edited by: Dr Champion N Nyoni (University of the Free State), Dr Werner Cordier (University of Pretoria) and Dr Liz Wolvaardt (University of Pretoria)

COVID-19 was declared a global pandemic in March 2020, resulting in various strategies aimed at reducing transmission. Consequently, planned learning and teaching activities were disrupted - and in some cases halted in many higher education institutions in Africa. Educators, administrators and students integrated innovations to their practice and/or research in health professions education during the COVID-19 pandemic. AJHPE calls for manuscripts for a special focus issue on 'Innovations in health professions education during the COVID-19 era'.

We are interested in the descriptions of innovations to educational practice and/ or educational research in health professions education during the COVID-19 era. Authors can submit their manuscripts as a short report or a full paper.

\section{'Why I will never go back to my old practice': Short report guidelines}

The purpose of this section is for authors to reflect on innovations to their educational practice and/or research during the COVID-19 era. The report should be up to 1500 words and need not have ethics clearance. The following guidelines should be followed for short reports for this special focus issue:

\section{Recommended headings}

- Why was the idea necessary (what was the problem)?

- What was tried (intervention)?

- Lessons learnt

- What will I keep in my practice?

- What will I not do?

- Evidence of innovation (QR code)

All short reports for this special focus issue will be expected to be submitted with a QR code that links to a 3-minute video that reflects the evidence of the innovation being reported. Authors are asked to show evidence of their innovation in the form of, e.g. videos, artefacts, collages.

For tips on how to make a video and QR code, follow the link or scan the QR code:
Click the link:

https://drive.google.com/file/d/1xcKzgOm70HqDvZ9Ed0zzmdFpcQdjyo $\mathrm{NC} /$ view? usp= sharing

Scan the QR code:

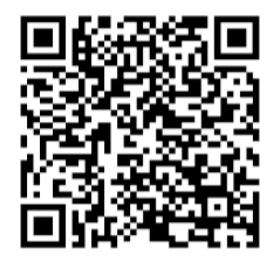

Full manuscripts/research

Manuscripts submitted as full research papers should have ethics clearance from an accredited institution, ethics body or ethics committee. The manuscripts should be a maximum of 3000 words, excluding abstract and bibliography.

Research articles should typically describe the background, methods, results and conclusion of an original research study that is aligned to the theme of the special focus issue. The article should contain the following headings:

- Structured abstract

- Introduction

- Methods

- Results

- Discussion

- Conclusion

Guidelines for research articles and the submission process: www.ajhpe.org.za

\section{Important dates}

The first closing date for the submission of manuscripts: 14 February 2021. Publication of the special focus issue: August 2021.

Afr J Health Professions Educ 2020;12(4):227. https://doi.org/10.7196/AJHPE.2020.v12i4.1458 